\title{
Conceptual Design of a New Sample Holder for the FRESCA Cable Test Station
}

\author{
B. Bordini, F. Regis, O. Crettiez, P. Fessia, M. Guinchard, J. C. Perez, and I. Sexton
}

\begin{abstract}
At present $\mathrm{Nb}_{3} \mathrm{Sn}$ Rutherford Cables seem to be the most suitable conductors for next generation superconducting accelerator magnets. These magnets will have a peak field in the coils larger than $10 \mathrm{~T}$ and the large Lorentz forces will impose coil pre-stresses significantly larger than $100 \mathrm{MPa}$. Since $\mathrm{Nb}_{3} \mathrm{Sn}$ is strongly sensitive to strain it is mandatory to characterize the cable under a transverse pressure comparable to the one experienced in future magnets. As a part of its High Field Magnet program, CERN is developing a sample holder for the FRESCA Facility that allows testing $10 \mathrm{~mm}$ wide superconducting Rutherford cables under a transverse pressure up to $200 \mathrm{MPa}$. The sample holder will be able to house cables up to $20 \mathrm{~mm}$ wide. In this paper the conceptual design is presented together with the experimental results of the mechanical test performed on a $40 \mathrm{~cm}$ long model. The results show that the structure can apply a transverse pressure larger than $200 \mathrm{MPa}$ on $10 \mathrm{~mm}$ wide cables with sufficiently high pressure homogeneity.
\end{abstract}

Index Terms-Cable testing, $\mathrm{Nb}_{3} \mathrm{Sn}$, strain sensitivity, transverse pressure.

\section{INTRODUCTION}

$\mathbf{N}$ EXT generation superconducting accelerator magnets will have a peak field in the coils larger than $10 \mathrm{~T}$ and the Lorentz forces will impose coil pre-stresses significantly larger than $100 \mathrm{MPa}$. Since $\mathrm{Nb}_{3} \mathrm{Sn}$, the superconductor more suitable for these magnets is strongly sensitive to strain, it is mandatory to perform a full characterization of the cable under a transverse pressure comparable to the one experienced in future magnets.

Only two test stations worldwide (at Twente University, The Netherlands - at the National High Magnetic Field Laboratory, Florida, USA) are capable of measuring superconducting Rutherford cables under high transverse pressure ( $>100 \mathrm{MPa}$ ); the cable length over which the pressure can be applied is approximately $5 \mathrm{~cm}$ at Twente [1] and $12 \mathrm{~cm}$ at NHMFL [2], [3]. These limited lengths might be a problem for accurate measurements. In the literature there are not much data regarding the behavior of $\mathrm{Nb}_{3} \mathrm{Sn}$ Rutherford cables under high transverse pressure [1]-[5] and some of the published results are contradictory. The FRESCA cable test facility at CERN [6] is capable to apply a uniform magnetic field over a cable length of $60 \mathrm{~cm}$, hence it has the potentiality to become the reference test station in the world for such type of measurements. It has

Manuscript received October 19, 2009. First published March 04, 2010; current version published May 28, 2010.

The authors are with CERN Geneva 23, $1211 \mathrm{CH}$, Switzerland (e-mail: bernardo.bordini@cern.ch).

Color versions of one or more of the figures in this paper are available online at http://ieeexplore.ieee.org.

Digital Object Identifier 10.1109/TASC.2009.2039707

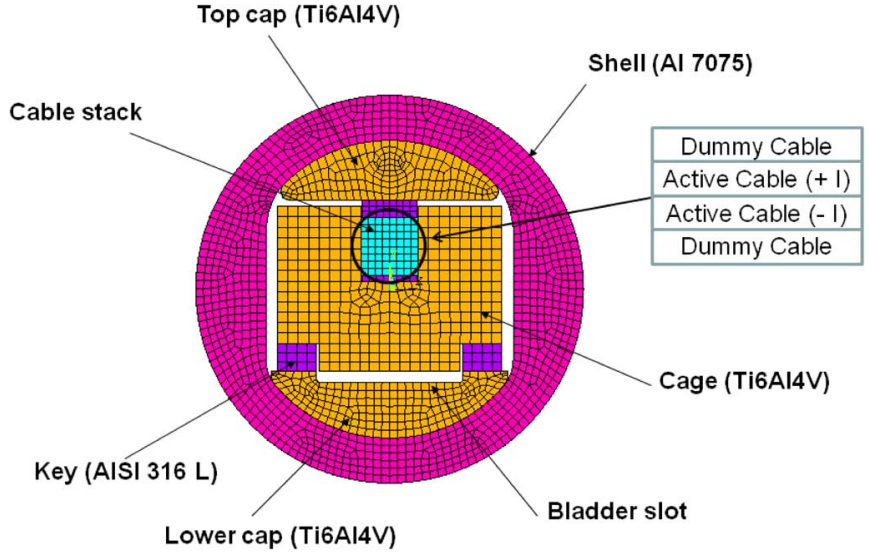

Fig. 1. Schematic of the new sample holder for the FRESCA facility.

been evaluated that at present the FRESCA sample holder can apply a maximum transverse pressure equal to $60 \mathrm{MPa}$ on $10 \mathrm{~mm}$ wide cables.

In this paper the conceptual design of a new sample holder for FRESCA that is able to apply a transverse pressure larger than $200 \mathrm{MPa}$ over $10 \mathrm{~mm}$ wide cables, is presented. The sample holder will house cables up to $2 \mathrm{~m}$ long and $20 \mathrm{~mm}$ wide at reduced pressure. High pressure will be applied only on the central $80 \mathrm{~cm}$ of the sample holder and a sufficiently high pressure homogeneity (ratio between minimum and maximum pressure larger than 0.9) will be guaranteed over $30 \mathrm{~cm}$ of the cable (where the applied transverse pressure and the applied magnetic field reach their maximum values). The sample holder components in contact with the cable are expected to have a longitudinal contraction at cold similar to the thermal contraction of the $\mathrm{Nb}_{3} \mathrm{Sn}$ (the critical properties of $\mathrm{Nb}_{3} \mathrm{Sn}$ are strongly sensitive to the longitudinal strain [7]). At present, a $40 \mathrm{~cm}$ long model of the sample holder central part has been manufactured and mechanically tested at room temperature and at $77 \mathrm{~K}$. In the paper we present the design and the experimental results of the mechanical test.

\section{Conceptual Design}

The main design difficulty is the combination of the limited dimension of the sample holder diameter (less than $70 \mathrm{~mm}$ because of the dimension of the magnet bore) with the high pressure that this structure has to apply to the cable. To overcome this difficulty the 'bladder and key' solution was selected [8]. It consists of inflating, at room temperature, a bladder inside the sample holder and then inserting keys of the appropriate dimensions that will maintain the pressure on the cable once the bladder is deflated and removed (see Figs. 1, 2). In 

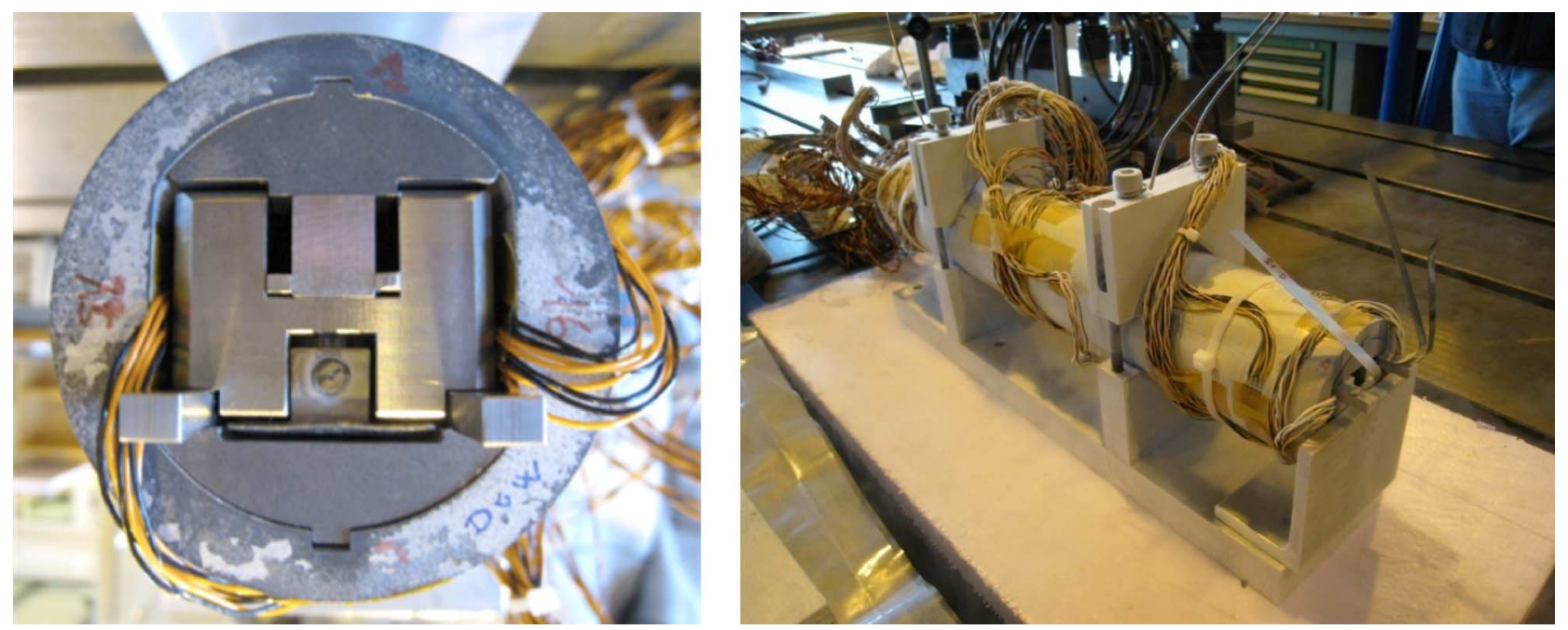

Fig. 2. Pictures of the short model of the new sample holder for the FRESCA cable test station at CERN.

TABLE I

MATERIAL PROPERTIES

\begin{tabular}{cccccc}
\hline \hline Material & \multicolumn{2}{c}{$E(\mathrm{GPa})$} & \multicolumn{2}{c}{$R_{p, 0.2}(\mathrm{MPa})$} & $\alpha \Delta T(\mathrm{~mm} / \mathrm{m})$ \\
& $293 \mathrm{~K}$ & $4.2 \mathrm{~K}$ & $293 \mathrm{~K}$ & $4.2 \mathrm{~K}$ & \\
\hline $\mathrm{Al} 7075$ & 73 & 80 & 480 & 690 & 4.0 \\
Ti6Al4V & 110 & 130 & 700 & 1000 & 1.7 \\
$\mathrm{Nb}_{3}$ Sn Cable $^{*}$ & 30 & 42 & - & - & 3.9 \\
$\mathrm{AISI} 316 \mathrm{~L}$ & 190 & 210 & 216 & 431 & 2.6 \\
\hline
\end{tabular}

* Stack of Rutherford cables insulated with fiberglass tape and impregnated with epoxy. Mechanical properties along transverse direction.

order to achieve the required key dimensions, shims of different thickness are placed on the top of the two keys. The pressure on the cable will further increase during the cool down thanks to the differential thermal contraction of the materials used to build the sample holder (Al 7075 for the shell and Ti6Al4V for the sample cage and the caps). This solution is successfully used for building $1 \mathrm{~m}$ long $\mathrm{Nb}_{3} \mathrm{Sn}$ magnets at the Lawrence Berkeley National Laboratory (USA) [8]. A stack of four cables is inserted into the cage (see Fig. 1): two active cables forming a closed current path are hedged in two dummy cables, reproducing a magnet-like environment. The materials properties (Young Modulus $-E$, the elastic limit $-R_{p 0.2}$, and the thermal contraction between room temperature and $4.2 \mathrm{~K}-\alpha \Delta T$ ) are listed in Table I.

Several 2D FEM models (ANSYS) corresponding to different assembly solutions have been developed [9]. No friction effects have been considered at this study stage. In this preliminary analysis, only the assembly and cool down phases were studied. The design criteria were set as follows:

- The peak pressure has to be about $200 \mathrm{MPa}$ for a $10 \mathrm{~mm}$ wide cable.

The transverse pressure has to be as uniform as possible along the cable width (variation within 10\%).

- For every part of the assembly, the peak equivalent stress (Von Mises criterion) must fulfill the material limit of yielding, assuming a safety factor equal to 1.5 .

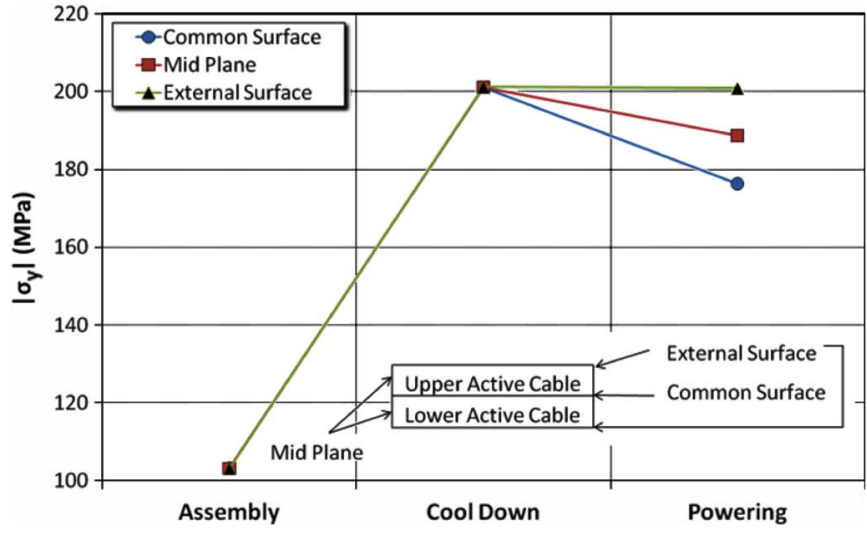

Fig. 3. P configuration: average transverse pressure $\sigma_{\mathrm{y}}$ on the active cables. Three simulation stages have been considered: assembly, cool-down ( $4.2 \mathrm{~K})$, and powering.

The configuration represented in Fig. 1 has been selected as the best out of three different solutions [9]. The effect of the Lorentz forces on the two active cables has been analyzed for this configuration only. Two different background field orientations have been considered: Parallel (P) and Anti-Parallel (AP) with respect to the cable self-field. In the calculation, the cable dimensions are $10.1 \times 2.6 \mathrm{~mm}$, the engineering critical current (taking into account the cable insulation and the impregnation) at $12 \mathrm{~T}$ and $4.2 \mathrm{~K}$ is equal to $990 \mathrm{~A} / \mathrm{mm}^{2}$ (which corresponds to a cable critical current equal to $26 \mathrm{kA}$ ) and the upper critical field $\mathrm{B}_{\mathrm{c} 2}$ at $4.2 \mathrm{~K}$ is equal to $24 \mathrm{~T}$ (representative values of a state of the art $\mathrm{Nb}_{3} \mathrm{Sn}$ Rutherford cable). Assuming these parameters and imposing an assembly interference which provides a target pressure on the active cables approximately equal to $200 \mathrm{MPa}$ before powering of the sample, the Lorentz forces produce a variation of the stress distribution that can be summarized as follows:

- P configuration: the magnetic forces tend to separate the two active cables leading to a stress reduction on the common surface (see Fig. 3). From $202 \mathrm{MPa}$ on the cables' external surface $(B=9.7 \mathrm{~T})$, the stress decreases 


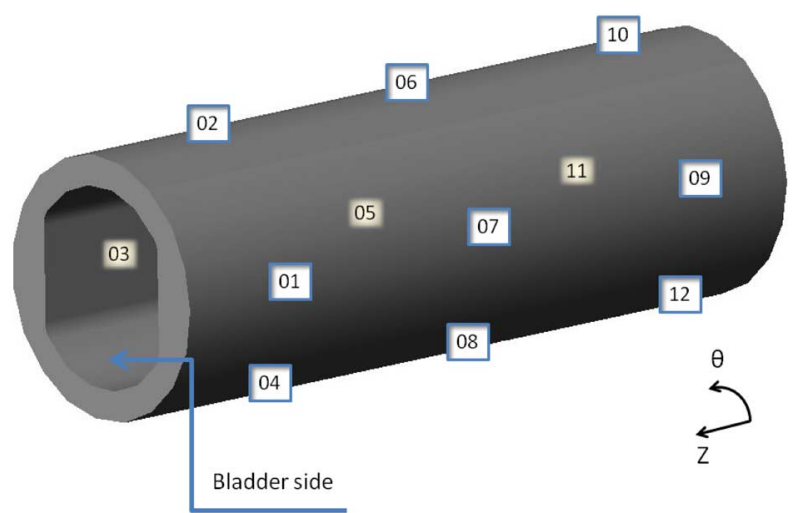

Fig. 4. Strain gages layout on the outer shell and relative reference system.

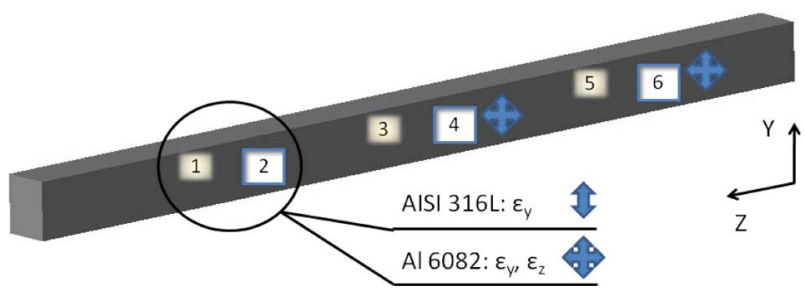

Fig. 5. Strain gages on the cable dummy stack and relative reference system. The gages are placed at $10-20-30 \mathrm{~cm}$ along the $40 \mathrm{~cm}$ dummy stack.

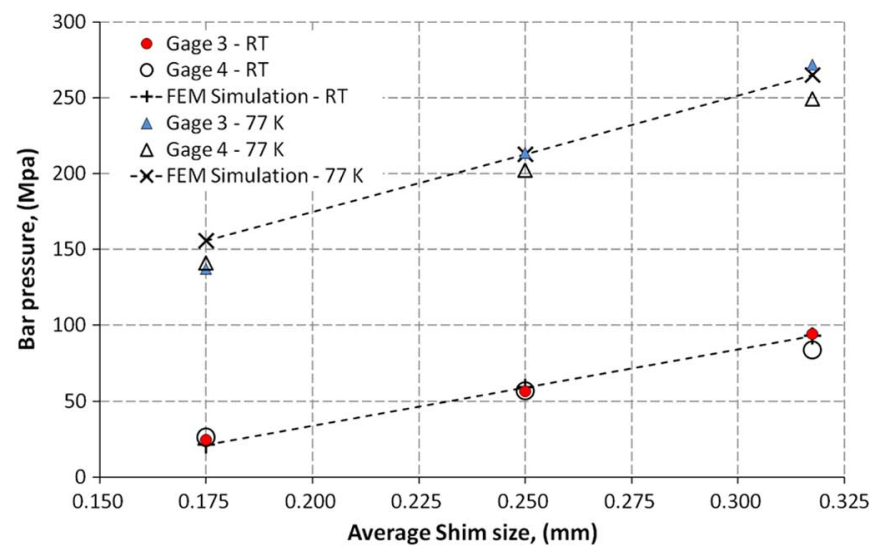

Fig. 6. Pressure $\left(\sigma_{\mathrm{y}}\right)$ applied on the stainless-steel bar as a function of the shim size at Room Temperature (RT) and at $77 \mathrm{~K}$ : comparison between the experimental measurements and the 3D ANSYS simulation.

to $176 \mathrm{MPa}$ on the common surface, where the peak field $B_{p}$ is observed (12.4 T).

- AP configuration: the magnetic forces tend to compress the two active cables leading to a stress increase on the common surface. From $202 \mathrm{MPa}$ on the cables' external surface $\left(B_{p}=10.4 \mathrm{~T}\right)$ the stress increases up to $230 \mathrm{MPa}$ on the common surface $(B=6.4 \mathrm{~T})$.

This scenario corresponds to an overall stress state in the structure that fulfills the Von Mises criterion with a safety factor larger than 1.5. From these results, one can conclude that the $\mathrm{P}$ configuration is the most suitable; indeed it allows achieving significantly higher peak fields on the cable, with a relatively small decrease of the pressure in the peak field region. Further analysis in the P configuration showed that $200 \mathrm{MPa}$ can be achieved in the peak field region while still satisfying the safety
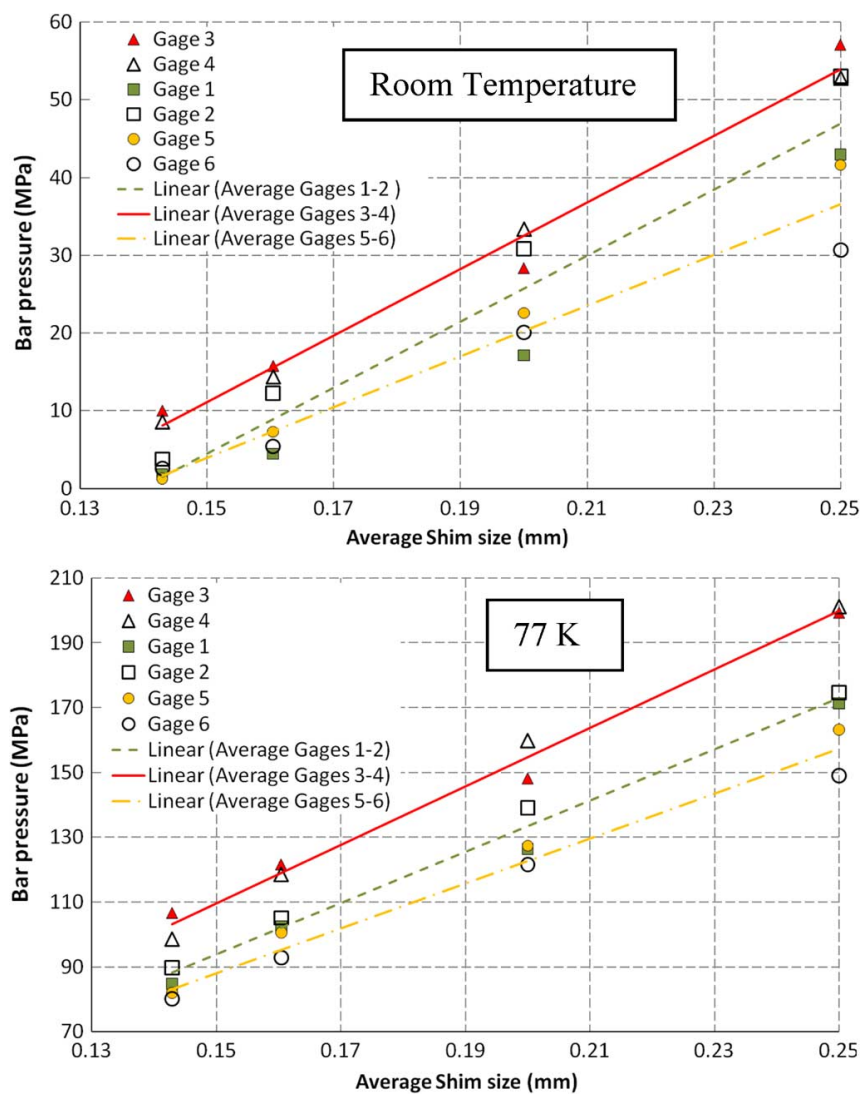

Fig. 7. Pressure distribution $\left(\sigma_{\mathrm{y}}\right)$ applied on the aluminum bar as a function of the shim size at room temperature and at $77 \mathrm{~K}$. The lines represent the three linear trends of the average pressure between the pairs of gages: $1-2 ; 3-4 ; 5-6$.

factor. Furthermore the pressure variation along the cable width is lower than $10 \%$ on the common surface.

\section{EXPERIMENTAL SET-UP OF THE SHORT MODEL}

The shell of the $40 \mathrm{~cm}$ long model has been instrumented with twelve gages, distributed along the length, measuring both longitudinal and azimuthal strains (see Fig. 4). The cable stack is replaced by a bar. Two experiments were carried out and in one case the bar was made of stainless steel AISI $316 \mathrm{~L}$ and in the other case was made of Aluminum Al6082 (ANTICORODAL). Several gages have been placed on the two bars to measure the longitudinal and transverse strains (see Fig. 5). Two longitudinal gages were also placed in the Ti6Al4V cage in correspondence to the bar gages 3 and 4 .

To compute the relative stress components, the measured strains are combined together using the following formulas:

$$
\begin{aligned}
\text { Shell } \quad \sigma_{\theta} & =E \frac{\varepsilon_{\theta}+\nu \varepsilon_{z}}{1-\nu^{2}} \\
\text { Bar } \quad \sigma_{y} & =E \frac{\varepsilon_{y}+\nu \varepsilon_{z}}{1-\nu^{2}}
\end{aligned}
$$

where $E$ and $\nu$ are respectively the Young modulus and the Poisson modulus.

\section{TEST RESUlts}

Before testing the whole assembly, the instrumented components were separately cooled down to $77 \mathrm{~K}$ and the strain gage 

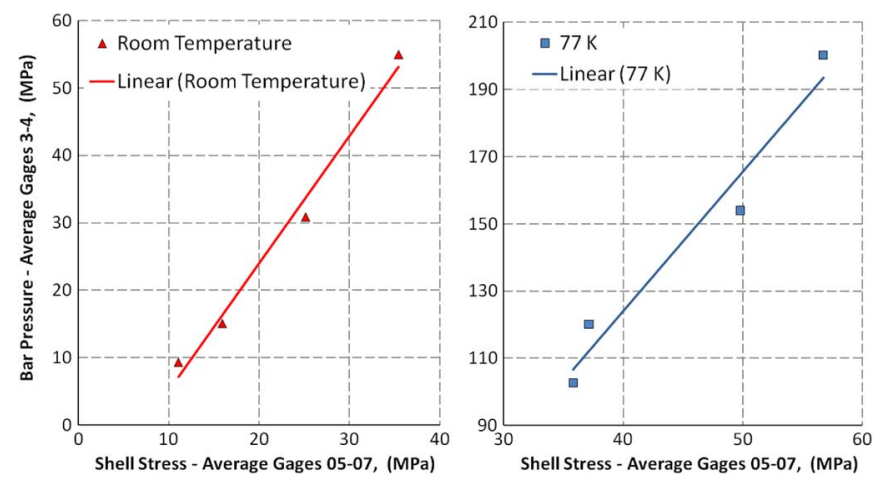

Fig. 8. Correlation between the average pressure in gages 3 and 4 of the aluminum bar and the average stress in gages 05 and 07 of the holder shell.

values recorded. These values were successively used in the cold measurements to compensate the strain gages.

The sample holder was at first tested using the stainless steel bar as cable stack. Fig. 6 shows the pressure applied in the center of the bar at room temperature and at $77 \mathrm{~K}$ for different values of the average shim thickness. To optimize the pressure distribution in the bar, the thickness of the two shims applied on the two keys was not necessary equal (maximum thickness difference: $50 \mu \mathrm{m})$. In the plot the experimental results are compared to 3D simulations using ANSYS. The simulation results are in good agreement with the data. The most relevant result from this test is the achievement of more than $250 \mathrm{MPa}$ on the bar, proving the effectiveness of the sample holder design. During the first test, gage number 6 was damaged and it was not possible reading the applied pressure, whereas gage number 5 , once the sample was cold, was always measuring a pressure about $25 \mathrm{MPa}$ lower than the one read by gages 3 and 4 . This behavior is due to an end-effect: the transverse pressure drops when approaching the ends of the sample holder.

In order to investigate the end-effect and to better study the distribution of the pressure on the cable stack, the aluminum bar was instrumented and tested (3D simulations were no carried out for this case). The aluminum was preferred to the stainless steel because it has a Young modulus and a thermal contraction coefficient that is closer to that one of the $\mathrm{Nb}_{3} \mathrm{Sn}$ cable stack, see Table I. Fig. 7 summarizes the experimental results obtained on the aluminum bar. From the plot one can conclude that: 1) the maximum difference between the pressures measured from two gages facing each other is less than $15 \mathrm{MPa}$; 2) at $77 \mathrm{~K}$ the end-effect generates a significant reduction of the applied pressure already $10 \mathrm{~cm}$ far from the bar ends, indeed gages 1, 2, 5, 6 measure a transverse pressure 14-22\% lower than gages 3, and 4.

A 3D FEM model predicted the end effect and showed that a $80 \mathrm{~cm}$ long model can guarantee a uniform transverse pressure along $30 \mathrm{~cm}$ of the bar before the pressure starts to drop towards the sample holder ends. Two longitudinal gages placed in the Ti6Al4V cage showed that the cage contraction at cold $(1.7-2 \mathrm{~mm} / \mathrm{m})$ is similar to the thermal contraction of the $\mathrm{Nb}_{3} \mathrm{Sn}$. Finally Fig. 8 shows the correlation between the pressure measured by the gages in the middle of the aluminum bar $(3,4)$ and the stress measured in the corresponding gages on the shell $(05,07)$.

From the test results one can conclude that at $77 \mathrm{~K}$ the pressure on the cable stack can be monitored to an accuracy of $\pm 10 \mathrm{MPa}$ through the gages on the shell. On the other hand, during the assembly phase, the gages on the metallic bars have been fundamental to set the appropriate thickness of the two shims to get a sufficiently homogeneous transverse pressure along the width of the cable. At this aim, since it is difficult to directly instrument with strain gages the impregnated cable stack, other solutions must be identified. A possibility might be to instrument the cable cage in the two regions that are in contact with the keys.

\section{CONCLUSION}

The experimental results of the short model demonstrated the design of a new sample holder for testing superconducting Rutherford cables up to a transverse pressure of $200 \mathrm{MPa}$ on $10 \mathrm{~mm}$ wide cables. At $77 \mathrm{~K}$ the maximum difference between the pressures measured from two gages facing each other is less than $15 \mathrm{MPa}$, indicating good homogeneity.

In order to have a sufficiently good homogeneity of the transverse pressure along a certain length of the cable stack, the length of the sample holder has to be properly set. A 3D FEM model (ANSYS) showed that a $80 \mathrm{~cm}$ long model can guarantee a central zone $30 \mathrm{~cm}$ long where the transverse pressure is uniform.

The pressure on the cable stack cannot be accurately monitored through the gages on the aluminum shell and the cable stack cannot be instrumented with strain gages. Hence for the final design will be mandatory to indentify other solutions to measure the distribution of the transverse pressure on the cable.

\section{REFERENCES}

[1] H. Ten Kate et al., "Critical current degradation in $\mathrm{Nb}_{3} \mathrm{Sn}$ cables under transverse pressure," IEEE Trans. Appl. Supercond., vol. 3, pt. 1, pp. 1334-1337, March 1993.

[2] D. Dietderich et al., "Critical current of superconducting Rutherford cable in high magnetic fields with transverse pressure," IEEE Trans. Appl. Supercond., vol. 9, pt. 2, pp. 122-125, June 1999.

[3] P. Bauer et al., Design of a Sample Holder for Measurements of $\mathrm{Nb}_{3} \mathrm{Sn}$ Critical Current Under Transverse Loading Conditions FNAL Tech. Report, TD 99-051, 1999.

[4] H. Boschman et al., "The effect of transverse loads up to $300 \mathrm{MPa}$ on the critical currents of $\mathrm{Nb}_{3} \mathrm{Sn}$ cables for LHC," IEEE Trans. Magn., vol. 27, pt. 2, pp. 1831-1834, March 1991.

[5] J. Van Oort et al., "The reduction of the critical current in $\mathrm{Nb}_{3} \mathrm{Sn}$ cables under transverse loads," IEEE Trans. Appl. Supercond., vol. 3, pt. 1, pp. 559-592, March 1993.

[6] A. Verweij et al., "1.9 K test facility for the reception of the superconducting cables for the LHC," IEEE Trans. Appl. Supercond., vol. 9, pt. 2, pp. 153-156, June 1999.

[7] B. ten Haken et al., "The influence of compressive and tensile axial strain on the critical properties of $\mathrm{Nb}_{3} \mathrm{Sn}$ conductors," IEEE Trans. Appl. Supercond., vol. 5, pt. 2, pp. 1909-1912, June 1995.

[8] S. Caspi, "The use of pressurized bladders for stress control of superconducting magnets," IEEE Trans. Appl. Supercond., vol. 16, pt. 2, pp. 358-361, June 2006.

[9] F. Regis, "Design of $\mathrm{Nb}_{3} \mathrm{Sn}$ Magnetic Devices to Study the Superconductor Degradation Under Variable Mechanical Load," PhD Thesis, , June 2009. 